\title{
STREET LIGHT GLOWS ON DETECTING THE VEHICLE MOVEMENT USING ARDUINO UNO
}

\author{
Ritam Sahu, Moyuri Shil, Rimpi Datta, Piyu Sarcar \\ ECE, Narula Institute of Technology, Kolkata, India
}

\begin{abstract}
This paper proposes how street light can be controlled in the presence or absence of vehicle to reduce the wastage of energy. The proposed work is accomplished by using Arduino UNO and sensors that will control the electricity based on night and object's detection. Meanwhile, a counter is set that will count the number of objects passed through the road. The beauty of the proposed work is that the wastage of unused electricity can be reduced. The aim of this project is to design a street light control system using Arduino UNO, which automatically turns on or off the street lights by detecting the movement of vehicles. The working of the project is explained here. When there is not any vehicle in front of the IR sensor module, the receiver can't get any infrared signal So the circuit remain in open loop condition and the lights are in off condition. When there is any vehicle in front of the IR sensor module, the receiver get the infrared signal. So the circuit is in close loop condition and the lights are in on condition with respect to the IR module. If the car blocks the first IR sensor, the first three LEDs are turned ON by the microcontroller. As the car moves forward and blocks the second IR sensor, the corresponding next three LEDs will be turned $O N$ and the first LED of the previous set is turned OFF. The process continues this way for all the IR Sensors and LEDs.
\end{abstract}

Keywords: Arduino Uno, IR sensor Module, Coding, Street Light, Energy consumption

Cite this Article: Ritam Sahu, Moyuri Shil, Rimpi Datta, Piyu Sarcar, Street Light Glows on Detecting the Vehicle Movement Using Arduino Uno, International Journal of Electrical Engineering \& Technology, 10(3), 2019, pp. 16-20.

http://iaeme.com/Home/issue/IJEET?Volume=10\&Issue=3

\section{INTRODUCTION}

Automation systems are being preferred over the manual mode because it reduces the use of energy to saves energy. These automation systems play an essential role in making our daily life more comfortable and facilitate users from ceiling fans to washing machines and in other applications. [5] Among all exciting applications, street lights play a vital role in our environment and also plays a critical role in providing light for safety during night-time travel. In this scenario, when the street lights are in working functionality over the whole night that consumes a lot of energy and reduces the lifetime of the electrical equipment such 
as electric bulb etc. Especially in cities' streetlights, it is a severe power consuming factor and also the most significant energy expenses for a city. In this regard, an intelligent lighting control system can decrease street lighting costs up to $70 \%$ and increase the durability of the equipment. [2]

The problem statement is to use it in the street lights as numerous roads having a large number of street lights glowing all the time whereas most of the time there are not any vehicle on the roads and the glowing lights are the source of wastage of energy all over the night.[3]

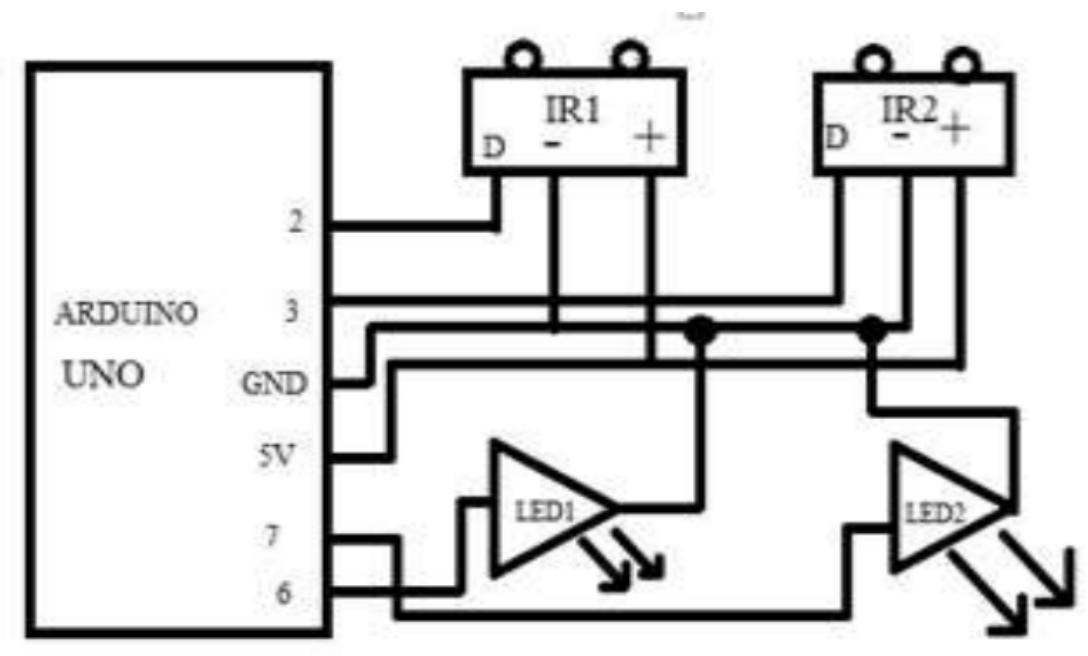

Figure 1 Architecture of Arduino

\section{HARDWARE COMPONENTS REQUIRED}

- Arduino Uno

- IR sensor Module(2 piece)

- $10 \mathrm{~mm}$ LED (4 piece)

- Power supply

- Male to male and Male to Female jumper wire

\section{CIRCUIT DESIGN}

- The circuit is made up of two IR module where the data pin of the first IR module is connected with pin no 2 of Arduino UNO using a male to female jumper wire.

- The second IR module's data pin is connected to the pin no 3 of Arduino UNO using a male to female jumper wire. [4]

- The positive pin of both the IR module is connected to the $+5 \mathrm{~V}$ in the Arduino UNO using male to female connecting wire. The negative pin connected with the GND of the Arduino UNO using the male to female jumper wires. 


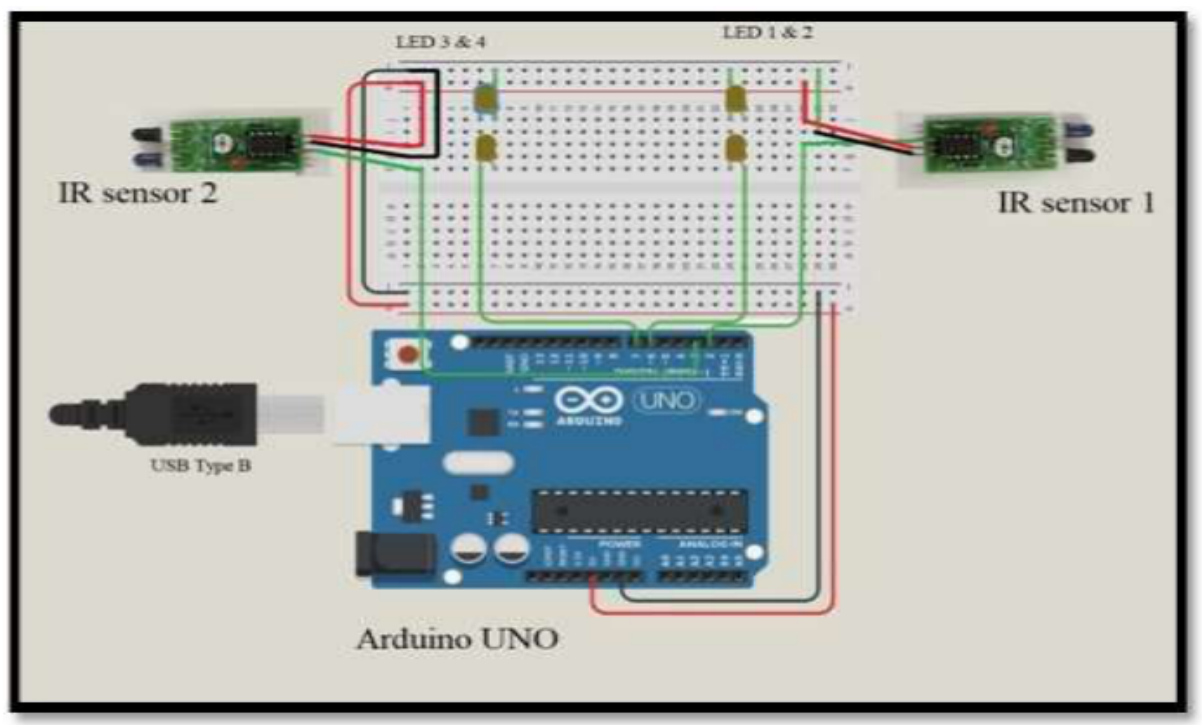

Figure 2 Circuit diagram with Hardware Components

- The positive terminal of first and second LEDs are connected with the pin no 6 of Arduino UNO using male to female connecting wire.

- The positive terminal of third and fourth LEDs are connected with the pin no 7 of Arduino UNO using male to female connecting wire.

- The negative terminal of all the LEDs are connected to the GND of the Arduino UNO using male to female jumper wires.

- The Arduino is connected with the laptop to switch on the circuit and it is done by a USB Type B to USB Type A adapter cable

- The Type B is connected with the Arduino and Type A USB cable is connected with the laptop of desktop with connect it with the Arduino software to upload the program[1].

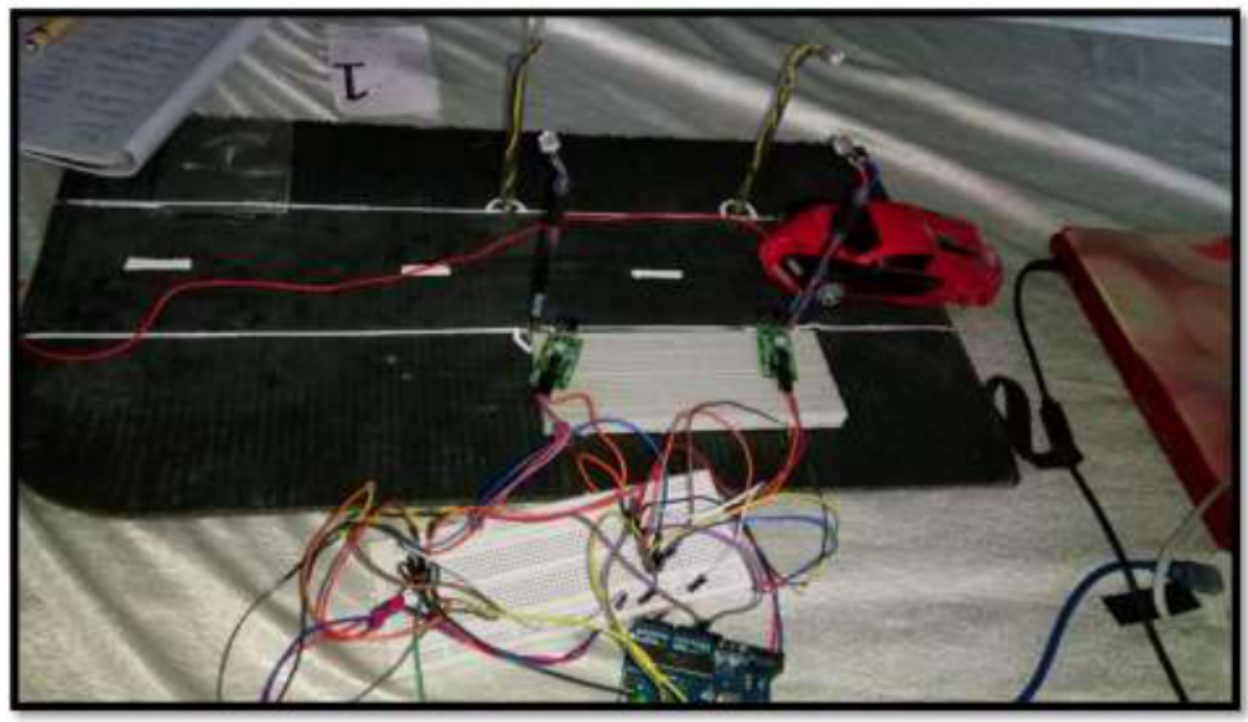

Figure 3 Experimental Setup 


\section{RESULT ANALYSIS}

Currently, in the whole world, enormous electric energy is consumed by the street lamps. Regular a street light consume 150-180 W Halogen. Regular a street light consume 150-180 W Halogen. But Light emitting diode. Sodium vapor lamp consumes $250 \mathrm{~W}$ on average. Mercury vapor lamps take up to $400 \mathrm{~W}$. Light Emitting Diode(Led) which lighting system we used today in a variety of ways, from energy saving in the average home of the consumer to streetlights in major urban cities. LED Technology accounted for an $85 \%$ reduction in energy cost. Our smart street light system consists of a LED light, a brightness sensor, a motion sensor and a short-distance communication network. The lights turn on before pedestrians and vehicles come and turn off or reduce power when there is no one. It will be difficult for pedestrians and drivers of vehicles to distinguish our smart street lamps and the conventional street lights, since our street lamps all turn on before they come. The present status and the future prospects of our smart start light project will be reviewed.

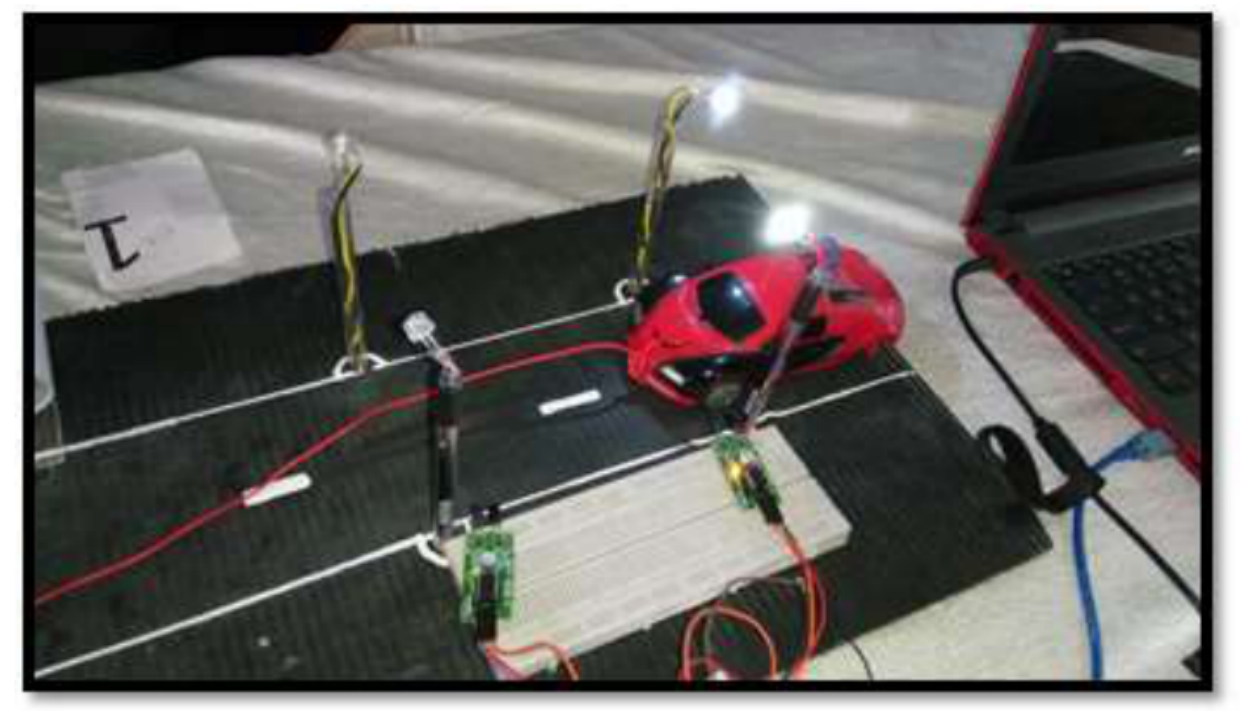

Figure 4. Design of Street light that glows on detecting the vehicle movement

Observation Table

\begin{tabular}{|l|c|c|}
\hline \multicolumn{1}{|c|}{ Vehicle Position } & LEDs In First Row & LEDs In Second Row \\
\hline No Vehicle & OFF & OFF \\
\hline In Front Of First IR & ON & OFF \\
\hline In Front Of Second IR & OFF & ON \\
\hline In Front Of Both IR & ON & ON \\
\hline
\end{tabular}

\section{CONCLUSION}

This street light control circuit can be used in normal roads, highways, express ways etc. This project can also be used in parking areas of malls, hotels, industrial lighting, etc. If the lighting system implements all LED lights, the cost of the maintenance can be reduced as the life span and durability of LEDs is higher than Neon based lights which are normally used as street lights. As the lights are automatically turned ON or OFF, huge amount of energy can be saved. So it will be so much beneficial if used. 


\section{REFERENCES}

[1] Vishalsoniindia 'Smart Street Light Using Ir Sensor With Arduino', 2018. [Online]. Available:https://www.instructables.com/id/Smart-Street-Light-Using-Ir-Sensor-WithArduino/ [Accessed: 16- May- 2019].

[2] Available:https://www.google.com/search?q=wastage + of + energy + street + lights\&rlz=1C1 CHBD_enIN777IN777\&source $=\operatorname{lnms} \&$ tbm $=$ isch \&sa $=$ X\&ved $=0$ ahUKEwjZ0tmo153iAhX p7nMBHZS7BIUQ_AUIDigB\&biw=1920\&bih=969\#imgrc=go9kkfP6nJ6IeM: [Accessed: 15- May- 2019].

[3] Available:https://www.researchgate.net/publication/326057835_Automatic_streetlights_th at_glow_on_detecting_night_and_object_using_Arduino

[4] D. A. Devi and A. Kumar, Design and Implementation of CPLD based Solar Power Saving System for Street Lights and Automatic Traffic Controller, International Journal of Scientific and Research Publications, Vol. 2, Issue11, November 2012.

[5] K. S. Sudhakar, A. A. Anil, K. C. Ashok and S. S. Bhaskar, Automatic Street Light Control System, International Journal of Emerging Technology and Advanced Engineering, Vol. 3, May 2013. 